\title{
Effectors of Plant Necrotrophic Fungi
}

\author{
Dandan Shao, Damon L. Smith, Mehdi Kabbage and Mitchell G. Roth* \\ Department of Plant Pathology, University of Wisconsin - Madison, Madison, WI, United States
}

Plant diseases caused by necrotrophic fungal pathogens result in large economic losses in field crop production worldwide. Effectors are important players of plant-pathogen interaction and deployed by pathogens to facilitate plant colonization and nutrient acquisition. Compared to biotrophic and hemibiotrophic fungal pathogens, effector biology is poorly understood for necrotrophic fungal pathogens. Recent bioinformatics advances have accelerated the prediction and discovery of effectors from necrotrophic fungi, and their functional context is currently being clarified. In this review we examine effectors utilized by necrotrophic fungi and hemibiotrophic fungi in the latter stages of disease development, including plant cell death manipulation. We define "effectors" as secreted proteins and other molecules that affect plant physiology in ways that contribute to disease establishment and progression. Studying and understanding the mechanisms of necrotrophic effectors is critical for identifying avenues of genetic intervention that could lead to improved resistance to these pathogens in plants.

\section{OPEN ACCESS}

Edited by:

Paloma Melgarejo,

Ministerio de Agricultura, Alimentación

y Medio Ambiente, Spain

Reviewed by:

Dov Bernard Prusky, Agricultural Research Organization,

Israel

Alejandro Perez-Garcia, University of Malaga, Spain

*Correspondence: Mitchell G. Roth

mgroth3@wisc.edu

Specialty section: This article was submitted to Plant Pathogen Interactions, a section of the journal

Frontiers in Plant Science

Received: 29 March 2021 Accepted: 03 May 2021 Published: 04 June 2021

Citation:

Shao D, Smith DL, Kabbage M and Roth MG (2021) Effectors of Plant

Necrotrophic Fungi.

Front. Plant Sci. 12:687713. doi: 10.3389/fp/s.2021.687713
Keywords: necrotrophic fungi, effector, programmed cell death, hypersensitive response, necrosis-inducing activity, defense suppression, sRNA effectors

\section{INTRODUCTION}

Plant pathogens are often categorized based on their relationship with host plants. These categories include biotrophs, which infect living plants with the objective of suppressing the plant immune system and acquiring nutrients from living cells; necrotrophs, which infect living plants with the objective of killing the plant upon or shortly after infection and acquiring nutrients from dead or dying tissues; and hemibiotrophs, which infect living plant tissues akin to biotrophs to first establish infection before "switching" to necrotrophy and killing the plant (Giraldo and Valent, 2013). Despite these seemingly distinct definitions, arguments can be made that trophic designations of some of these pathogens are convoluted as we learn more about the complexities of their interactions with a given host plant (Kabbage et al., 2013, 2015; Toruño et al., 2016). A common theme that unifies plant-associated fungal pathogens despite their different colonization and nutrient acquisition strategies, is the use of effectors during plant colonization (Giraldo and Valent, 2013). While more frequently studied in biotrophic and hemibiotrophic fungi, effectors in necrotrophic fungi have only recently begun to receive significant attention. This review discusses the roles of effectors from necrotrophic and late-stage hemibiotrophic fungi in disease development, including induction of plant cell death, suppression of plant immunity, and the activation of susceptibility genes (inverse gene-for-gene relationship).

Abbreviations: PCD, programmed cell death; CWDE, cell wall degrading enzymes; HR, hypersensitive response; HST, host selective toxin; QTL, quantitative trait loci; OA, oxalic acid; PR, pathogenesis related; ROS, reactive oxygen species; BNS, biotrophy/necrotrophy switch; SM, secondary metabolites; sRNAs, non-coding small RNAs. 
As efficient plant killers, necrotrophic fungi are infamous for causing significant losses in the field and in storage worldwide, and diseases that cause annual threats to food security (Fones et al., 2020). Managing diseases caused by necrotrophic fungi requires multiple approaches, though fungicide applications are the most common approach currently used. The heavy reliance on spray regimes is costly, poses environmental challenges, and can lead to the emergence of resistant populations (Brent and Hollomon, 2007). Therefore, control strategies through improving genetic resistance are desirable, yet our understanding of the molecular intricacies between the plant and necrotrophs lags behind their biotrophic counterparts. Notably, a broad understanding of the role of effectors in the pathogenic development of these fungi is lacking. As their roles in this pathogenic system are clarified, necrotrophic effectors and their plant targets will become targets for manipulation to confer resistance to these pathogens.

Effector proteins are narrowly defined as small, cysteine rich, secreted proteins used by pathogens to manipulate plant cellular responses to the benefit of the pathogen. Effectors from plant biotrophic/hemibiotrophic fungi have been studied by generations of plant pathologists since the gene-for-gene theory was put forward by Flor (1971), and their ability to suppress plant immunity, manipulate plant physiology, and be recognized by host defense mechanisms is well documented (Koeck et al., 2011). In contrast, necrotrophs were previously thought to use a bruteforce approach, including the deployment of large repertoires of cell wall degrading enzymes (CWDE) and broad-spectrum toxins to kill plant cells in advance of fungal growth, obtaining nutrients from dead tissue. However, recent advances in genome and transcriptome sequencing, and computational prediction tools suggest there are hundreds of putative effectors present in necrotrophic genomes (Sperschneider et al., 2016; Derbyshire et al., 2017; Lopez et al., 2018; Le Marquer et al., 2019). The surprisingly large number of effectors identified in necrotrophs indicates that the mechanisms deployed by necrotrophic fungi are more intricate than initially hypothesized. Indeed, functional studies of effectors referenced in this review support this notion, and suggest a clear contribution of these molecules to the pathogenic success of fungal necrotrophs.

Herein, we broadly discuss the participation of effectors from necrotrophic and late stage hemibiotrophic fungi in disease development, plant cell death modulation, and both the suppression and the hijacking of plant immune responses. In addition to proteinaceous effectors, we also discuss the recent discovery of small RNAs produced by necrotrophic fungi and their role in disease establishment.

\section{PLANT CELL DEATH-INDUCING EFFECTORS}

By definition, necrotrophs kill host cells and acquire nutrients from dead cells. It is thus reasonable to speculate that necrotrophic fungi may utilize effectors to coopt host programmed cell death (PCD). Indeed, many examples of effectors from necrotrophic fungi have been reported for their cell death-inducing activities. Inducing cell death in plants can release many plant-derived compounds that are toxic to fungi, so it is also important to consider fungal proteins involved in tolerating this environment. These detoxification mechanisms were the subject of another recent review on necrotrophic fungi (Westrick et al., 2021), and will not be covered here.

\section{Necrotrophic Effectors That Hijack R-Mediated Resistance}

The hypersensitive response (HR) is a localized cell death program triggered by the recognition of effectors by plant resistance (R) proteins to confer resistance against biotrophs and hemibiotrophs, and is commonly referred to as EffectorTriggered Immunity (ETI) (Jones and Dangl, 2006). Remarkably, this genetic program can be hijacked by necrotrophs to their own benefit, considering their trophic lifestyle. This phenomenon is termed effector-triggered susceptibility (ETS) due to the activation of plant defense responses often including cell death, leading to susceptibility to necrotrophs (Table 1; Williams and Dickman, 2008). These necrotrophic effectors were initially termed "host selective toxins" (HST), and are typically effective in a narrow range of plant hosts (Tan et al., 2010).

An excellent example of this is found in the tan spot pathogen of wheat, Pyrenophora tritici-repentis. P. tritici-repentis secretes two effectors, PtrToxA (Tuori et al., 1995) and PtrToxB (Friesen and Faris, 2004), that are critical for disease development. Susceptibility in wheat is conferred by the Tsn 1 gene, a classical plant R gene with conserved features such as a serine/threonine protein kinase (S/TPK) domain, nucleotide binding site (NBS), and leucine rich repeat (LRR) domain. Tsn1 is required for plant susceptibility to PtrToxA, although Tsn1 does not directly interact with PtrToxA (Faris et al., 2010). PtrToxA translocates into plant cells possibly through the recognition of arginineglycine-aspartic acid (RGD) motif in the protein by a plant surface receptor (Manning and Ciuffetti, 2005) and eventually localizes to chloroplasts leading to light-dependent reactive oxygen species (ROS) accumulation and cell death (Ciuffetti et al., 2010). To date, the precise role of Tsn 1 in ToxA sensitivity is unknown, though the evidence is clear that Tsn1 plays a strong role in sensitivity to PtrToxA. PtrToxA sensitivity in plants lacking Tsn1 have also been reported (Manning and Ciuffetti, 2015), suggesting the presence of other susceptibility factors linked to PtrToxA. Similarly, PtrToxB also requires wheat genotypes which possess the single dominant susceptibility locus Tsc2 (Friesen and Faris, 2004), though the specific PtrToxB sensitivity gene in this locus remains elusive (Corsi et al., 2020). In contrast to PtrToxA, PtrToxB appears to function extracellularly in the plant apoplast (Figueroa et al., 2015). However, the extracellular interactors and specific mode of action of PtrToxB are yet to be identified.

Parastagonospora nodorum is another necrotroph with hostselective effectors that target specific host genotypes of wheat and other cereals, causing $P$. nodorum leaf blotch (Solomon et al., 2006). Nine host-specific effectors from $P$. nodorum and their corresponding host susceptibility loci have been identified and characterized (reviewed by Cowger et al., 2020). 
TABLE 1 | Effectors that induce plant cell death in an inverse gene-for-gene manner.

\begin{tabular}{|c|c|c|c|c|}
\hline Pathogen name & Effector & Protein domain/function & Plant susceptibility gene or locus & References \\
\hline \multirow[t]{2}{*}{ Pyrenophora tritici-repentis } & PtrToxA & $\begin{array}{l}\text { arginine-glycine-aspartic acid } \\
\text { (RGD) motif }\end{array}$ & Tsn1 & $\begin{array}{l}\text { Manning and Ciuffetti, 2005, } \\
\text { 2015; Manning et al., 2007; } \\
\text { Faris et al., } 2010\end{array}$ \\
\hline & PtrToxB & $\mathrm{N} / \mathrm{A}$ & Tsc2 & $\begin{array}{l}\text { Friesen and Faris, 2004; } \\
\text { Figueroa et al., } 2015\end{array}$ \\
\hline \multirow[t]{9}{*}{ Parastagonospora nodorum } & SnToxA & $\begin{array}{l}\text { arginine-glycine-aspartic acid } \\
\text { (RGD) motif }\end{array}$ & Tsn1 & Friesen et al., 2006 \\
\hline & SnTox1 & N/A & Snn1 & Liu et al., 2004, 2012, 2016 \\
\hline & SnTox2 & $\mathrm{N} / \mathrm{A}$ & Snn2 & Friesen et al., 2007 \\
\hline & SnTox3 & N/A & Snn3 & Liu et al., 2009 \\
\hline & SnTox4 & N/A & Snn4 & Abeysekara et al., 2009 \\
\hline & SnTox5 & $\mathrm{N} / \mathrm{A}$ & Snn5 & Friesen et al., 2012 \\
\hline & SnTox6 & N/A & Snn6 & Gao et al., 2015 \\
\hline & SnTox7 & $\mathrm{N} / \mathrm{A}$ & Snn7 & Shi et al., 2015 \\
\hline & SnTox8 & N/A & Snn8 & Faris et al., 2007 \\
\hline Cochliobolus heterostrophus & ChToxA & N/A & unknown & Lu et al., 2015 \\
\hline Cochliobolus sativus; (Bipolaris sorokiniana) & BsToxA & $\mathrm{N} / \mathrm{A}$ & Tsn1 & McDonald et al., 2018 \\
\hline Corynespora cassiicola & cassiicolin & N/A & unknown & de Lamotte et al., 2007 \\
\hline Cochliobolus victoriae & victorin & N/A & Vb in oat, LOV1 in Arabidopsis & $\begin{array}{l}\text { Wolpert et al., 1985; Lorang } \\
\text { et al., } 2007\end{array}$ \\
\hline
\end{tabular}

SnToxl was the first HST identified in $P$. nodorum that requires a single host susceptibility locus Snn1 to confer susceptibility (Liu et al., 2004). Snn1 genes allow recognition of SnTox1 in a light-dependent manner, triggering hallmarks of PCD including an oxidative burst, strong up-regulation of pathogenesis-related (PR) genes, and DNA laddering (Liu et al., 2012). Notably, SnTox1 was also shown to have a chitin binding domain, which is thought to play a role in protecting fungal cell walls from degradation by plant chitinases (Liu et al., 2016). This feature may also be important to prevent the release of chitin monomers, which are recognized by pattern recognition receptors (PRRs) and subsequent activation of immune responses (discussed in section 2: Plant Immunitysuppressing Effectors). Another $P$. nodorum effector, SnToxA, was shown to be almost identical to PtrToxA from $P$. triticirepentis and shares the same host susceptibility gene, Tsn 1 (Friesen et al., 2006), suggesting that $P$. tritici-repentis acquired ToxA from $P$. nodorum by horizontal gene transfer (Friesen et al., 2006). Seven additional $P$. nodorum HSTs, SnTox2, SnTox3, SnTox4, SnTox5, SnTox6, SnTox7, and SnTox8, have been identified along with their corresponding susceptibility loci, Snn2 (Friesen et al., 2007), Snn3 (Liu et al., 2009), Snn4 (Abeysekara et al., 2009), Snn5 (Friesen et al., 2012), Snn6 (Gao et al., 2015), Snn7 (Shi et al., 2015), and Snn8 (Faris et al., 2007), respectively. Due to the complex nature of the wheat genome, specific genes within susceptibility loci that are responsible for the susceptibility to $P$. nodorum effectors remain unknown. However, these studies report that the SnTox2-Snn2, SnTox4-Snn4, SnTox5-Snn5, and SnTox6-Snn6 interactions are all dependent on light and very likely share the similar downstream pathways leading to the induction of PCD, thus subverting this plant resistance mechanism for the benefit of the necrotrophic pathogen.
In the maize pathogen Cochliobolus heterostrophus, a ToxAlike gene (ChTOXA) was found to share both sequence and structure similarities with PtrToxA, with the exception of the putative translocation RGD motif (Lu et al., 2015). It induces light-dependent cell death in sensitive maize lines, however, the maize gene responsible for susceptibility to ChToxA is yet to be identified ( $\mathrm{Lu}$ et al., 2015). Recent genome analyses of three C. sativus isolates (anamorph Bipolaris sorokiniana), the causal agent for multiple diseases in wheat and barley, have also revealed the presence of a ToxA-like gene that shares homology with PtrToxA and SnToxA (McDonald et al., 2018). Pathogenicity assays show that isolates harboring ToxA genes are more virulent on Tsn1 wheat genotypes (McDonald et al., 2018), suggesting ToxA from C. sativus functions similarly to other ToxA effectors.

Corynespora cassiicola is a necrotroph that produces a proteinaceous HST known as cassiicolin, a small, secreted, cysteine-rich phytotoxic protein (de Lamotte et al., 2007). C. cassiicola is the causal agent of leaf spot or leaf fall disease on many economically important crops, including rubber tree, cocoa, and soybean (Silva et al., 2000). At least seven Cas genes encoding isoforms of cassiicolin have been identified in various C. cassiicola isolates (Cas1 to Cas7) (Déon et al., 2014; Lopez et al., 2018). In a recent study, a cas 1 mutant generated from a highly aggressive isolate lost all virulence in susceptible rubber tree clones (Ribeiro et al., 2019). Quantitative trait loci (QTL) analysis has identified potential loci associated with the rubber tree susceptibility to cassiicolin and other C. cassiicola effectors (Ribeiro et al., 2019), however, specific sensitivity genes within these QTL are yet to be explored.

One example of a non-traditional effector is victorin, produced by Cochliobolus victoriae, the causal agent of Victoria blight in oats. Victorin functions within a narrow range of plant hosts, so it is considered a HST. Victorin is 
non-traditional because it is a mixture of hexapeptides that were previously thought to be synthesized independent of ribosomes. Surprisingly, recent evidence revealed that victorin is in fact ribosomally synthesized (Kessler et al., 2020). The Vb gene in oat (Wolpert et al., 1985) and LOV1 gene in Arabidopsis thaliana determines the sensitivity to victorin (Lorang et al., 2007). Similar to susceptibility genes against $S$. nodorum and $P$. tritici-repentis, LOV1 in Arabidopsis also encodes a characteristic $\mathrm{R}$ gene with NBS-LRR domains (Lorang et al., 2007) and the recognition of victorin elicits apoptotic-like cell death which facilitates the infection of $C$. victoriae as a necrotroph. The Pc-2 gene in oat confers disease resistance against rust pathogen Puccinia coronata, and is tightly linked to the $\mathrm{Vb}$ gene, complicating breeding efforts against both rust and blight diseases (Meehan and Murphy, 1946; Litzenberger, 1949). Pc-2 and Vb genes are now considered to be the same gene that confers resistance to Puccinia coronata, but susceptibility to C. victoriae (Wolpert et al., 2002; Lorang et al., 2012). This constitutes a remarkable example of how necrotrophs can evolve mechanisms to highjack $\mathrm{R}$ genes against biotrophs to their own benefit. Additional nontraditional HSTs are discussed in section 1.6.

\section{Effectors That Hijack PCD Pathways}

Besides inducing PCD via an inverse gene-for-gene manner, necrotrophic effectors can also target or hijack specific components of the PCD pathway. Upon pathogen attack, plants often increase the level of cytosolic calcium, which stimulates calcium-dependent signaling mechanisms that mediate plant defense responses, often culminating in HR or PCD (Lam et al., 2001). Thus, mimicking such responses can be beneficial to necrotrophs.

Endopolygalacturonases are commonly secreted by fungi as CWDE, releasing oligogalacturonides as by-products. However, one endopolygalacturonase purified from Sclerotinia sclerotiorum also increases intracellular calcium and triggers hallmarks of apoptosis-type cell death, including cytochrome c release from mitochondria and activation of caspase 9-like and caspase 3-like enzymes in soybean cells (Zuppini et al., 2005). In contrast, the oligogalacturonides byproducts were unable to initiate PCD (Binet et al., 2001), revealing that the S. scleortiorum endopolygalacturonase alone is the trigger of PCD, independent of its presumed enzymatic activity (Zuppini et al., 2005).

Sspg1d is another endopolygalacturonase from S. sclerotiorum that contributes to PCD induction in plants (Wang et al., 2009). Instead of functioning as a CWDE, Sspg1d specifically interacts with the C2 domain of the canola IPG-1 protein. C2 domain proteins have calcium-binding affinity and are likely involved in calcium-dependent signal transduction (Evans et al., 2004) and defense responses (Laxalt et al., 2001). IPG-1 subcellular localization is determined by calcium concentrations, indicating a role in calcium dependent signaling. IPG-1 is also highly upregulated during a compatible interaction with S. sclerotiorum, leading to susceptibility. As several C2 domain proteins were reported to be PCD regulators (Yang et al., 2007) and another known endopolygalacturonase of S. sclerotiorum induced PCD in host plant (Zuppini et al., 2005), Sspg1d is proposed to promote PCD by interfering with the activity of IPG-1 as a negative regulator of PCD (Wang et al., 2009). However, not all endopolygalacturonases have the capacity to coopt plant cell death components, and likely function as classical CWDEs. For instance, endopolygalacturonases from Botrytis cinerea (BcPG1 and BcPG2) induce necrotic cell death by provoking a loss of cell wall integrity, as is the case of many CWDEs produced by fungal pathogens (Kars et al., 2005).

\section{Cell Death Inducing Effectors Containing Conserved Domains}

The term "necrosis-inducing" can be misleading, as necrosis typically refers to cell death involving non-physiological or non-programmed events due to overwhelming injury. Effectors that contain the necrosis and ethylene-inducing peptide (NEP) domain have been shown to induce cell death in plants, and despite necrosis in the name, this mechanism appears to be physiological for some NEPs (Table 2).

The first NEP (Nep1) was isolated from Fusarium oxysporum infecting a coca plant (Erythroxylum coca) (Bailey, 1995), and Nep1 also triggers cell death in Arabidopsis (Bae et al., 2006). Two F. oxysporum Nep1 homologs were identified in S. sclerotiorum and referred to as SsNep1 and SsNep2 (Dallal-Bashi et al., 2010). SsNep2 was highly expressed during infection on Brassica napus leaves and caused PCD that is dependent on calcium signaling (Dallal-Bashi et al., 2010). Nep-like proteins (NLPs) appear to be conserved in many filamentous fungi, some of which have cell death-inducing qualities and others do not (Oome and Van den Ackerveken, 2014). Many NLPs have a calcium binding pocket and may also be influenced by intracellular calcium concentrations (Oome and Van den Ackerveken, 2014), suggesting that these molecules may influence plant cells into committing suicide. In the lily pathogen Botrytis elliptica, two NLPs (BeNEP1 and BeNEP2) were identified and display cell death-inducing activity in a range of dicots, but not monocots, including its host lily (Staats et al., 2007). Therefore, NLPs are not essential virulence factors or HSTs for B. elliptica on lily, but may be a horizontally acquired feature that led to a competitive advantage allowing colonization of additional hosts (Staats et al., 2007). In hemibiotrophic fungus Colletotrichum higginsianum, six NLPs were identified (ChNLPs) based on the presence of NEP domains. Among them, only ChNLP1 and ChNLP2 were expressed exclusively during the transition to necrotrophy and induced potent cell death when overexpressed in Nicotiana benthamiana (Kleemann et al., 2012). Additional NLPs from Colletotrichum orbiculare and Fusarium virguliforme are also reported to induce cell death in tobacco and soybean, respectively (Yoshino et al., 2012; Chang et al., 2016). The postharvest pathogen Penicillium expansum contains two NLP effectors, PeNLP1 and PeNLP2 that cause cell death when transiently expressed in N. benthamiana (Levin et al., 2019). PeNLP1 is highly induced compared to PeNLP2 during infection of apple fruit, and deletion of PeNLP1, but not PeNLP2, led to a significant reduction in lesion size (Levin et al., 2019).

Cerato-platanin family proteins (CPPs) are another secreted protein family found only in filamentous fungi and reported to cause phytotoxicity, including in B. cinerea (Frías et al., 2011), 
TABLE 2 | Effectors with necrosis-inducing or other known domains.

\begin{tabular}{|c|c|c|c|c|}
\hline Pathogen name & Effector & Protein domain/function & Plant target & References \\
\hline \multirow[t]{3}{*}{ Sclerotinia sclerotiorum } & SsNep1 & necrosis and ethylene-inducing peptides (NEP) & unknown & Dallal-Bashi et al., 2010 \\
\hline & SsNep2 & NEP & unknown & Dallal-Bashi et al., 2010 \\
\hline & $\mathrm{SsCP} 1$ & Cerato-platanin protein & unknown & Yang G. et al., 2018 \\
\hline \multirow[t]{7}{*}{ Botrytis cinerea } & BcSp1 & Cerato-platanin protein & unknown & Frías et al., 2011 \\
\hline & BcGs1 & glucan 1,4-alpha-glucosidase & unknown & Zhang et al., 2015 \\
\hline & BcXyn11A & xylanase & unknown & Noda et al., 2010; Frías et al., 2019 \\
\hline & BcXyl1 & xylanase & unknown & Yang Y. et al., 2018 \\
\hline & BcXYG1 & xyloglucanase & unknown & Zhu et al., 2017 \\
\hline & BcCrh1 & Congo red hypersensitivity transglycosylase & unknown & Bi et al., 2020 \\
\hline & BclEB1 & IgE binding protein & osmotin & Frías et al., 2016; González et al., 2017 \\
\hline \multirow[t]{2}{*}{ Botrytis elliptica } & BeNEP1 & NEP & unknown & Staats et al., 2007 \\
\hline & BeNEP2 & NEP & unknown & Staats et al., 2007 \\
\hline \multirow[t]{2}{*}{ Colletotrichum higginsianum } & ChNLP1 & NEP & unknown & Kleemann et al., 2012 \\
\hline & ChNLP2 & NEP & unknown & Kleemann et al., 2012 \\
\hline Heterobasidion annosum & HaCPL2 & Cerato-platanin protein & unknown & Chen et al., 2015 \\
\hline Rhizoctonia solani & AGLIP1 & lipase domain & unknown & Li et al., 2019 \\
\hline
\end{tabular}

S. sclerotiorum (Yang G. et al., 2018), Heterobasidion annosum (Chen et al., 2015), and Magnaporthe oryzae (Yang et al., 2009). $\mathrm{BcSpl1}$, a CPP from B. cinerea, is the sixth most abundant protein in the secretome of this fungus (Frías et al., 2011), and mutants lacking BcSpll show reduced virulence compared to wild-type strains. The infiltration of purified $\mathrm{BcSpl} 1$ protein causes rapid cell death in tomato, tobacco, and Arabidopsis leaves in a dosedependent manner, and this cell death response was accompanied by hallmarks of the HR response; autofluorescence, ROS burst, electrolyte leakage, and cytoplasm shrinkage (Frías et al., 2011). Furthermore, the BcSpl1 activity requires the membrane-bound co-receptor BAK1 for full activity, which is known to enhance immune signaling responses in plants (Schwessinger and Ronald, 2012). The detection of cell surface receptors associated with PCD suggest a physiological and subtle cell death induction by necrotrophs and their effectors. This supports a growing number of hypotheses that some necrotrophic fungi have evolved mechanisms to hijack and induce plant PCD for their own benefit of colonizing and feeding off the dead plant tissues (Kabbage et al., 2013).

Another CPP was recently identified in S. sclerotiorum (SsCP1), a close relative of $B$. cinerea, as an important contributor to virulence (Yang G. et al., 2018). Similar to BcSpl1, SsCP1 induces cell death when transiently overexpressed in $N$. benthamiana in a dose-dependent manner (Yang G. et al., 2018). Interestingly, SsCP1 also interacts with PR1 in the apoplast, presumably inhibiting the antifungal activity of PR1 and promoting infection (Yang G. et al., 2018). A CPP-like protein HaCPL2 was also found in the basidiomycete Heterobasidion annosum sensu stricto, which is a necrotrophic fungal pathogen of Scot pine (Pinus sylvestris) (Chen et al., 2015). HaCPL2 is highly induced during infection of $P$. sylvestris, and induces cell death, phytoalexin production, and upregulation of multiple defense genes in the non-host plant Nicotiana tabacum (Chen et al., 2015). Recombinant HaCPL2 also induces cell death and inhibits root growth in $P$. sylvestris, accompanied by an upregulation of genes related to jasmonic acid (JA)/ethylene (ET) signaling pathways in P. sylvestris (Chen et al., 2015). However, whether HaCPL2 triggers programmed or necrotic-like cell death in its host requires further investigation.

Lipase domain containing proteins constitute another protein family with a role in cell death induction. In AG1IA anastomosis group of Rhizoctonia solani, the causal agent of rice sheath blight, the effector AGLIP1 contains this lipase domain and elicits cell death, with or without a functional lipase domain in non-host N. benthamiana, but not Arabidopsis (Li et al., 2019). Ectopic expression of AGLIP1 in transgenic Arabidopsis led to a suppression of defense-response genes, suggesting AGLIP1 also suppresses immune signaling (Li et al., 2019). Whether cell death elicited by AGLIP1 in plants is due to recognition of AGLIP1 by certain plant receptors, direct phytotoxicity, or lipase activity remains to be investigated.

There is a special group of "necrosis-inducing" proteins (NIP) referred to as catalytic NIPs due to their glycosyl hydrolase activities. Another group of NIPs which lack a catalytic domain will be discussed in the next section. Catalytic NIPs not only degrade plant cell walls like CWDEs, but also induce plant defense responses that are often unrelated to their catalytic activity (Kars et al., 2005). The latter property contrasts with endopolygalacturonases, like BcPG1 and BcPG2 discussed above, whose necrotizing activity is dependent on enzymatic activity. Several catalytic NIPs have been reported in B. cinerea (Noda et al., 2010; Zhang et al., 2015; Frías et al., 2016; González et al., 2017; Zhu et al., 2017; Yang Y. et al., 2018; Bi et al., 2020). One of these catalytic NIPs, BcGs1, is a glucan 1,4-alphaglucosidase, and infiltration of BcGs1 in tobacco and tomato leaves induces strong cell death, accumulation of ROS, and upregulation of PR genes, suggesting an HR-like PCD (Zhang et al., 2015). Interestingly, BcGs1-treated plants induce disease resistance against tobacco mosaic virus, Pseudomonas syringae pv. tomato DC3000, and against B. cinerea itself (Zhang et al., 2015). This study demonstrates that BcGs1 acts as an elicitor that 
induces a strong, localized immune response that likely primes plant defenses for subsequent infections. However, $B$. cinerea actively secretes BcGs1, which may trigger HR-like PCD at the point of infection, allowing $B$. cinerea to take advantage of the subsequent cell death leading to susceptibility.

Botrytis cinerea xylanase BcXyn11A (Noda et al., 2010; Frías et al., 2019) and BcXyl1 (Yang Y. et al., 2018) are catalytic NIPs with xylan degrading activity, but also induce HR-like cell death including ROS production and electrolyte leakage, which is independent of their xylan degrading activity. In addition, a 26-amino acid peptide derived from BcXy1, and a 25-amino acid peptide derived from BcXyn11a are sufficient for eliciting HR-like cell death (Yang Y. et al., 2018; Frías et al., 2019). Recognition of BcXy1 is mediated by plant apoplastic LRR receptor-like kinases BAK1 and SOBIR1 (Yang Y. et al., 2018). Similarly, a xyloglucanase BcXYG1 was reported to have cell death- and immune response-eliciting activities which were also independent of xyloglucanase activity (Zhu et al., 2017).

BcIEB1 from $B$. cinerea is another elicitor that induces HRrelated symptoms of cell death, ROS burst, autofluorescence, and electrolyte leakage (Frías et al., 2016). Additional work on BcIEB1 found that this protein, specifically a 35-amino acid conserved region called ieb35, interacts with a plant osmotin, which belongs to family 5 of PR proteins in plant cells and the interaction protected $B$. cinerea from the antifungal osmotin (González et al., 2017). Moreover, osmotin was shown to interfere with the cell death induced by BcIEB1, but was not directly involved in the elicitation of defense responses (González et al., 2017).

\section{Effectors With Unknown Protein Domains}

Recent bioinformatic studies have revealed repertoires of small secreted proteins (SSPs) in several phytopathogens that might contribute to virulence, and many of them are cysteine-rich, small-sized proteins without known protein domains (Wen et al., 2019; Denton-Giles et al., 2020). Predicted effectors with no known domains from a transcriptome study of S. sclerotiorum were recently screened for cell death-inducing activity (Seifbarghi et al., 2020). One such effectors, SsNE2, induces cell death in $N$. benthamiana (Seifbarghi et al., 2020). Interestingly, this cell death activity requires plant receptor-like kinases, suggesting a hijacking of immune signaling (Seifbarghi et al., 2020). Similarly, two NIPs without catalytic domains, ZtNIP1 and ZtNIP2, were also identified as putative effectors from Zymoseptoria tritici (Ben M'Barek et al., 2015). Further characterization of ZtNIP1 and ZtNIP2 indicated that infiltration of both proteins induces cell death, but only in select wheat cultivars. The genetic basis for susceptibility to these effectors is yet to be determined (Ben M'Barek et al., 2015).

In the conifer pathogen Heterobasidion parviporum, a SSP without any known protein domains, HpSSP35.8, was identified as a necrotrophic effector protein secreted during infection (Wen et al., 2019). Overexpression of HpSSP35.8 induces a strong cell death phenotype and activates PR genes, the "WRKY" transcription factors, genes involved in JA/ET-signaling, and chitinase genes, all of which are known defense responses (Wen et al., 2019). This response suggests that the cell death observed is an HR-like response, though HpSSP35.8 also had significant effects on chlorophyll and photosynthesis, which could indicate that the cell death observed is truly necrosis. It is interesting to note that one of the HpSSP3.5-triggered plant responses, the induction of chitinase genes, was also observed in P. nodorum SnTox1 - wheat Snn1 interaction, where SnTox1 has chitin binding activity for protecting $P$. nodorum from degradation of induced plant chitinases (Liu et al., 2016). Whether HpSSP35.8 has the same chitin-binding activity is yet to be investigated, though it has no predicted chitin-binding domain.

A comparative analysis of secretomes of three closely related members of Sclerotiniaceae, B. cinerea, S. sclerotiorum, and Ciborinia camelliae, revealed an expansion of a class of cysteinerich SSPs in the genome of $C$. camelliae (73 CcSSPs) compared to only one homolog in both $B$. cinerea (BcSSP2) and S. sclerotiorum (SsSSP3). These are called C. camelia-like SSPs (CCL-SSPs) due to their abundance in C. camelliae (Denton-Giles et al., 2020). This SSP family is conserved in many other plant pathogens, but for the most part, have not been characterized. Interestingly, recombinant BcSSP2 and SsSSP3 induce significantly stronger and faster cell death than any CcSSP tested (Denton-Giles et al., 2020). Furthermore, both BcSSP2 and SsSSP3 are capable of inducing cell death in plant hosts (camelliae) and nonhosts (N. benthamiana) (Denton-Giles et al., 2020), suggesting that CCL-SSPs might act as non-host-specific, broad cell death inducers in a wide range of plants.

\section{Effectors That Play Roles in Biotrophy-Necrotrophy Switch (BNS)}

Because hemibiotrophic fungal pathogens display both biotrophic and necrotrophic qualities, stage specific effectors play a key role in the establishment of infection. Some effectors secreted from hemibiotrophs induce cell death at the later stages of infection, but others facilitate the biotrophy-necrotrophy switch (BNS). During infection of lentil (Lens culinaris) by the hemibiotroph Colletotrichum truncatum, effector CtNUDIX (NUcleoside DIphosphate linked to some other moiety X) regulates the BNS (Bhadauria et al., 2013). In bacteria and mammals, proteins containing Nudix hydrolase domains catalyze hydrolysis of mutagenic nucleotides and toxic components and function as cellular surveillance enzymes to maintain physical homeostasis (Safrany et al., 1999; Xu et al., 2001; McLennan, 2006). During infection, CtNUDIX is exclusively expressed during the late biotrophic stage precisely at the BNS. CtNUDIX localizes to the plant plasma membrane and induces severe HRlike cell death when overexpressed in N. benthamiana (Bhadauria et al., 2013). CtNUDIX-overexpressing strains of C. truncatum and $M$. oryzae fail to induce disease symptoms on lentil and barley, respectively, but light-brown discoloration is observed, which is suspected to be HR-like cell death on infected plants (Bhadauria et al., 2013). These results suggest that the timely secretion of CtNUDIX is key to normal disease progression, and its premature secretion likely triggered cell death in the biotrophic phase, preventing these two hemibiotrophs from establishing infection. 
Another example of an effector involved in BNS is found in Colletotrichum graminicola, the causal agent of anthracnose of maize (Vargas et al., 2012). The C. graminicola effector, Cgfl, is a metalloprotease fungalysin that is highly induced during the switch to the necrotrophic stage (Vargas et al., 2012). SanzMartín et al. (2016) further characterized this metalloprotease as a predicted chitinase degrading enzyme, and deletion mutants of Cgfl displayed severely reduced virulence on plants. This suggests that Cgfl may be involved in suppressing chitin-triggered immunity as a virulence mechanism, particularly during the BNS when it is most highly expressed.

In Collectotrichum lentis, the effector ClToxB is also induced during the BNS in virulent races of C. lentis (Bhadauria et al., 2015). Intriguingly, ClToxB shares extensive sequence similarity with PtrToxB from $P$. tritici-repentis, suggesting $\mathrm{ClToxB}$ is a potential HST on lentils. Indeed, RNAi strains of C. lentis with reduced expression of $\mathrm{ClToxB}$ show impaired virulence compared to the wild-type strain, and its transient overexpression failed to induce cell death in the non-host tobacco $N$. tobacum (Bhadauria et al., 2015). Interestingly, if susceptibility to ClToxB is conditioned by an R-like protein, as is the case in the P. triticirepentis pathosystem, this would constitute a remarkable example where R-mediated processes can participate in both resistant and susceptible outcomes in this hemibiotroph depending on the phase of infection. However, further work is required to identify the plant target(s) of ClToxB, and to better understand the biochemical context in which it functions.

\section{Non-traditional Effectors and Host-Selective Toxins (HSTs)}

Fungal secondary metabolism has seen a resurgence of research attention in recent years (Keller, 2019). Many well-studied HSTs are fungal secondary metabolites (SM), and have strong diseaseinducing effects in plants (Stergiopoulos et al., 2013; Tsuge et al., 2013). These fungal SM range from small modified peptides to molecules with complex chemical structures, and have various modes of action specific to susceptible host genotypes.

For example, HC-toxin is a cyclic tetrapeptide from Cochliobolus carborum, the causal agent of Northern corn leaf spot, that suppresses expression of host defense genes by targeting histone-deacetylases in susceptible plants (Brosch et al., 1995; Walton, 2006). The chlorinated peptides Peritoxin A and B produced by the sorghum pathogen Periconia circinata induce apoptotic cell death (Dunkle and Macko, 1995) in sorghum plants harboring NBS-LRR type of R gene $P c-B$ (Nagy and Bennetzen, 2008). This suggests that $P$. circinata deploys peritoxins to exploit PCD mechanisms in sorghum similar to that of victorin in oats (Lorang et al., 2012), though a direct interaction between peritoxins and R-genes has yet to be determined.

Mycotoxins like aflatoxins, trichothecenes, and structurally related toxins are major concerns in food contamination because of their high toxicity to mammals (Arunachalam and Doohan, 2013; Fasoyin et al., 2019; Luciano-Rosario et al., 2020). However, many of these fungal SM also contribute to plant colonization and pathogenicity. For instance, Aspergillus flavus and P. expansum are common post-harvest pathogens of a broad range of storage crops, and also strong producers of toxic SM (Kelley et al., 2012; Luciano-Rosario et al., 2020). Patulin and citrinin produced by $P$. expansum contribute to aggressiveness and establishment in some plant cultivars, although neither is required for infection (Snini et al., 2016; Touhami et al., 2018; Luciano-Rosario et al., 2020). These post-harvest pathogens rely heavily on secreted CWDE (Fountain et al., 2014), though other proteinaceous effectors and virulence factors have also been identified and are covered in section "Cell Death Inducing Effectors Containing Conserved Domains” (Levin et al., 2019; Luciano-Rosario et al., 2020).

Additional examples of SM that contribute to virulence are found in Alternaria and Fusarium species. Alternaria alternata f. sp. lycopersici deploys AAL toxins that induce apoptotic-like phenotypes in sensitive tomato plants (Wang et al., 1996), but not in plants harboring the Ascl (Alternaria stem canker resistance gene 1) gene (Brandwagt et al., 2000). Additional A. alternata pathotypes produce similar toxins that have a wide range of negative effects on plant cells, and have been summarized elsewhere (Meena and Samal, 2019). Deoxynivalenol, a mycotoxin produced by Fusarium graminearum, accumulates to high concentrations in the necrotic phase of infection and elicits strong ROS burst (Mudge et al., 2006; Desmond et al., 2008), but can actually inhibit PCD at low concentrations (Diamond et al., 2013).

\section{PLANT IMMUNITY-SUPPRESSING EFFECTORS}

Accumulating evidence suggests that necrotrophs interact with their hosts in a more subtle and complex way, beyond cell death induction. Recent studies show that some necrotrophic effectors do in fact suppress plant immunity (Table 3), a commonly accepted feature of effectors from biotrophic and early-stage hemibiotrophic pathogens.

\section{Effectors Preventing Pathogen Recognition and Immunity}

The lysin motif (LysM) domain is a widespread protein motif found in many organisms, including fungi and plants, and is known for binding peptidoglycans and chitin (Kaku et al., 2006; Miya et al., 2007; Buist et al., 2008; Shimizu et al., 2010). During infection, secreted plant chitinases lead to degradation of fungal cell walls, releasing fungal cell wall fragments like chitin or chitosan oligomers. These oligomers are detected by plant extracellular receptors with LysM domains, thus triggering an immune response (Thomma et al., 2011). Many biotrophic and hemibiotrophic fungal effectors also contain the LysM motif and competitively bind to chitin or its oligomers, interfering with plant recognition of these oligomers (de Jonge et al., 2010; Marshall et al., 2011; Kombrink et al., 2017). A recent study in the necrotrophic fungus $R$. solani found that RsLysM, the only putative LysM effector present in the genome of $R$. solani AG2-2IIIB (Wibberg et al., 2016), suppresses chitin-triggered immunity by binding to chitin (Dölfors et al., 2019). Notably, RsLysM does not protect hyphae from chitinolytic activity of 
TABLE 3 | Plant immunity-suppressing effectors in necrotrophic fungi.

\begin{tabular}{|c|c|c|c|c|}
\hline Pathogen name & Effector & Class/Domain & Function & References \\
\hline Cochliobolus carborum & HC-toxin & Secondary metabolite & Disrupt plant histone deacetylaces & Brosch et al., 1995; Walton, 2006 \\
\hline Colletotrichum graminicola & Cgfl & Metalloprotease & Degrade plant chitinases & Vargas et al., 2012; Sanz-Martín et al., 2016 \\
\hline \multirow[t]{3}{*}{ Sclerotinia sclerotiorum } & SSITL & Integrin-like domain protein & $\begin{array}{l}\text { Disruption of calcium signaling, } \\
\text { induce SA/suppress JA signaling }\end{array}$ & Nomura et al., 2012; Tang et al., 2020 \\
\hline & Oxalic acid & Elicitor & $\begin{array}{l}\text { Suppress ROS burst and callose } \\
\text { deposition }\end{array}$ & Williams et al., 2011 \\
\hline & SsEWCA & Chitinase & Suppress chitin-triggered immunity & Martínez-Cruz et al., 2021 \\
\hline \multirow[t]{5}{*}{ Botrytis cinerea } & Bc-siR3.1 & Small RNA & $\begin{array}{l}\text { Reduce expression of key immune } \\
\text { signaling genes }\end{array}$ & Weiberg et al., 2013 \\
\hline & Bc-siR3.2 & Small RNA & $\begin{array}{l}\text { Reduce expression of key immune } \\
\text { signaling genes }\end{array}$ & Weiberg et al., 2013 \\
\hline & Bc-siR5 & Small RNA & $\begin{array}{l}\text { Reduce expression of key immune } \\
\text { signaling genes }\end{array}$ & Weiberg et al., 2013 \\
\hline & $\mathrm{Bc}-\mathrm{siR} 37$ & Small RNA & $\begin{array}{l}\text { Reduce expression of key immune } \\
\text { signaling genes }\end{array}$ & Wang et al., 2017 \\
\hline & BcEWCA & Chitinase & Suppress chitin-triggered immunity & Martínez-Cruz et al., 2021 \\
\hline \multirow[t]{3}{*}{ Rhizoctonia solani } & RsLysM & LysM containing protein & Chitin binding & Wibberg et al., 2016; Dölfors et al., 2019 \\
\hline & RsRlpA & Lipoprotein & Protease inhibition & Charova et al., 2020 \\
\hline & RsEWCA & Chitinase & Suppress chitin-triggered immunity & Martínez-Cruz et al., 2021 \\
\hline Valsa mali & VmEP & Unknown & Unknown & Li et al., 2015 \\
\hline Verticillium dahilae & VdPDS1 & Chitin deacetylase & $\begin{array}{l}\text { Modify chitin to non-immunogenic } \\
\text { chitosan }\end{array}$ & Gao et al., 2019 \\
\hline
\end{tabular}

plant chitinases (Dölfors et al., 2019), as some other chitinbinding effectors like Cladosporium fulvum Avr4 does, but likely prevents recognition by plant chitin receptors (van den Burg et al., 2006). A new family of chitin-related effectors were recently identified in the biotrophic fungus Podosphaera xanthii which causes powdery mildew in cucurbits, and termed effectors with chitinase activity (EWCA) (Martínez-Cruz et al., 2021). These EWCA degrade chitin oligomers, therefore suppressing chitin-triggered immunity. Phylogenetic analyses revealed that EWCA orthologs are present in many necrotrophic fungi too, including B. cinerea, S. sclerotiorum, and $R$. solani (MartínezCruz et al., 2021). Whether these EWCA orthologs also act as inhibitors of chitin-triggered immunity in necrotrophs is yet to be determined. Similarly, a polysaccharide deacetylase (PDA1) effector was recently identified in the hemi-biotrophs Verticillium dahliae and F. oxysporum, which converts chitin to chitosan thus preventing chitin-triggered immune signaling in cotton (Gao et al., 2019). VdPDA1 is highly expressed early in infection and likely contributes to a successful biotrophic phase of $V$. dahlia infection, as PDA1 knockout mutants had severely reduced virulence (Gao et al., 2019).

Another $R$. solani AG2-2IIIB effector protein, RsRlpA, encodes a rare lipoprotein A-like that has immunity suppressing activity (Charova et al., 2020). RsRlpA is highly induced during early infection of sugar beets, and its overexpression in N. benthamiana suppresses HR imposed by C. fulvum Avr4 (Charova et al., 2020). RsRlpA shares sequence homology to papain-like inhibitors which are known for blocking activity of papain-like cysteine proteases (PL) that help induce PCD and other immune responses in plants (reviewed by MisasVillamil et al., 2016). Indeed, the HR inhibition by RsRlpA is associated with protease inhibitor activity, inhibiting a plant cathepsin that is a known PLCP (Bárány et al., 2018). Various other plant protease activities, including caspase-like activities, have been shown to function in the execution of plant PCD (Kabbage et al., 2017), so suppression of HR-like cell death through other protease inhibition mechanisms may also be present in plant-pathogen interactions. AGLIP1 from $R$. solani strain AG1IA, which was mentioned in the previous section, also inhibits plant immunity, but by currently unknown mechanisms (Li et al., 2019).

In the apple Valsa canker fungus, Valsa mali, seven out of 70 randomly selected candidate effectors (referred to as VmEPs) were shown to suppress BAX-induced PCD in $N$. benthamiana ( $\mathrm{Li}$ et al., 2015). The Bax protein belongs to the cell death antagonist Bcl-2 family of proteins and was demonstrated to induce cell death resembling defenserelated HR in plants (Lacomme and Santa Cruz, 1999; Kabbage et al., 2017). Suppression of Bax-associated PCD by VmEPs indicates that these effectors inhibit plant HR-related resistance during infection.

Overall, the suppression of cell death in these examples are counterintuitive considering the trophic lifestyle of these pathogens. However, we speculate that early stages of infection by necrotrophs may require a suppression of cell death to establish infection before triggering the opposite, in a manner that is analogous to hemibiotrophic infections. Indeed, the prototypical necrotroph $S$. sclerotiorum is proposed to have a brief biotrophic phase before quickly switching to necrotrophy (Kabbage et al., 2015). Alternatively, it may be possible that not all cell deaths are created equal, and the type of cell death triggered by the plant may differ from the one imposed by the pathogen, and therefore needs 
to be suppressed. In accordance, an interplay between autophagic and apoptotic cell deaths with opposing outcomes was reported in necrotrophic fungal infections (Kabbage et al., 2013), and a deeper understanding of the native plant PCD mechanisms is needed (Kabbage et al., 2017).

\section{Effectors Altering Hormone, Calcium Signaling, and Oxidative Burst for Improper Immune Responses}

Phytohormones play critical roles in disease resistance and in general, salicylic acid (SA) signaling pathways are induced for successful resistance against biotrophs (Glazebrook, 2005), while induction of JA signaling pathways typically lead to successful defense against necrotrophs (Gfeller et al., 2010). As extensive crosstalk between the SA and JA signaling pathways have been demonstrated (Kunkel and Brooks, 2002), it's reasonable to expect pathogen effectors to manipulate hormone signaling pathways to suppress hormone mediated resistance (El Oirdi et al., 2011). For example, fungal integrin-like (ITL) proteins are important for fungal development (Corrêa et al., 1996; Zhu et al., 2013), but SsITL from S. sclerotiorum is secreted during plant infection and interacts with chloroplast-localized calcium sensing receptor, promoting SA biosynthesis (Nomura et al., 2008, 2012; Tang et al., 2020). This influx of SA leads to a suppression of JA signaling, culminating in enhanced susceptibility to $S$. sclerotiorum. In a hypovirulent strain of S. sclerotiorum, SsITL is significantly downregulated, supporting its role in virulence (Li et al., 2008).

A non-traditional effector produced by $S$. sclerotiorum that leads to improper immune responses is oxalic acid (OA). The effects of $\mathrm{OA}$ are broad, initially creating a strong reducing environment that dampens immune responses like ROS burst, callose deposition, and autophagy (Williams et al., 2011; Kabbage et al., 2013). Later in infection, accumulation of OA can induce ROS and trigger apoptotic-like PCD, contributing to necrotrophic success (Kabbage et al., 2013).

\section{SRNA EFFECTOR-LIKE MOLECULES}

Recent studies have revealed that non-coding small RNAs (sRNAs) derived from necrotrophic fungi can also be delivered into host cells, hijack plant RNAi machinery, and silence plant genes that are involved in immunity (Weiberg et al., 2013; Wang et al., 2016, 2017). As small, secreted molecules that affect

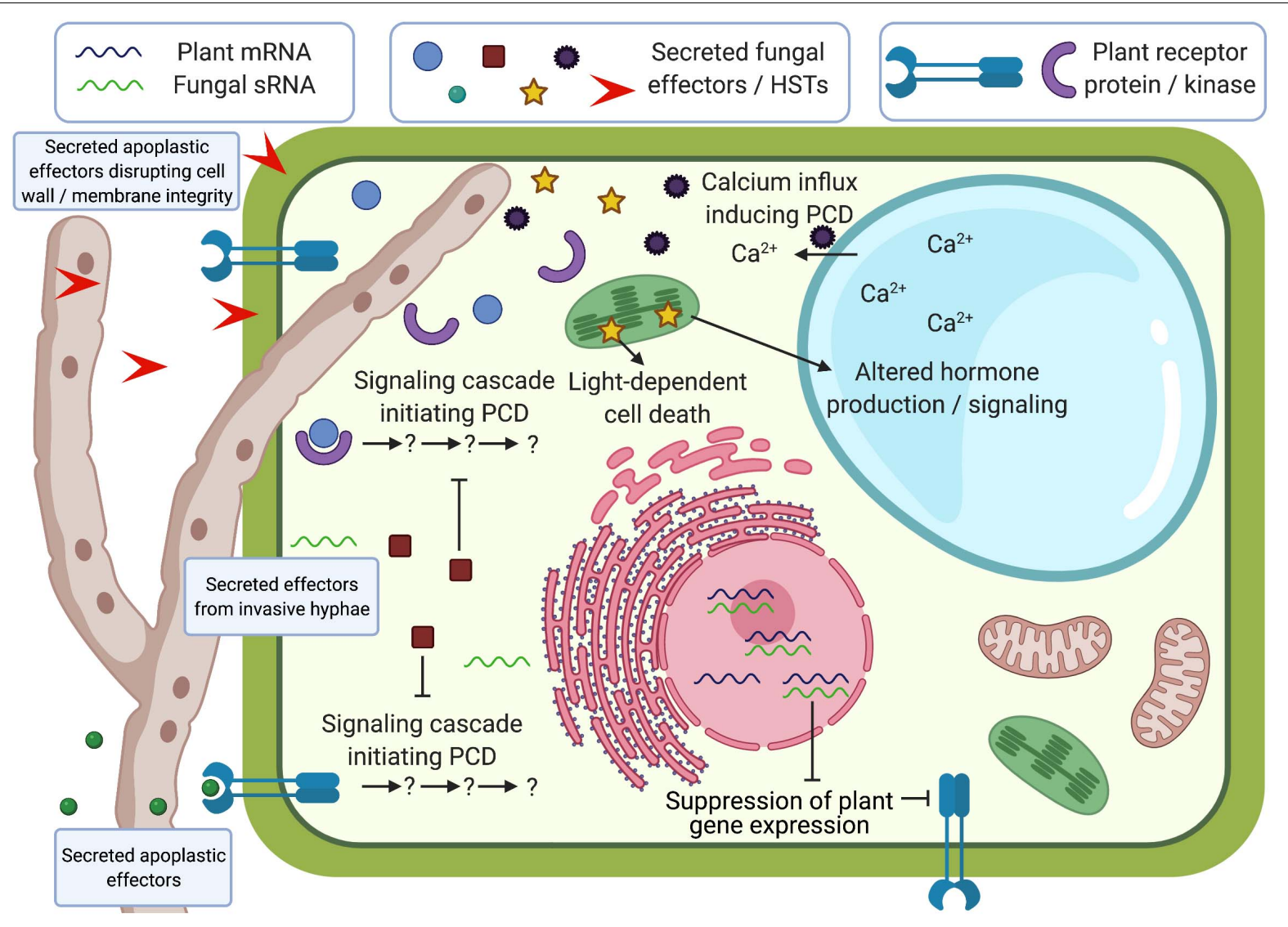

FIGURE 1 | Schematic representation of effector functions during plant-fungal necrotroph interactions. Effectors can be secreted into the apoplast or into plant cells from invasive hyphae, and can disrupt cell wall/membrane integrity, initiate programmed cell death (PCD), suppress PCD, alter hormone signaling, affect signaling cascades that use calcium ion fluxes, or suppress plant gene expression through small non-coding RNAs (sRNAs). Some of these processes have been shown to be light-dependent. Created with BioRender.com. 
plant physiology, sRNAs are now often considered effector-like molecules, despite being non-proteinaceous (Weiberg and Jin, 2015). Pathogen sRNAs are mainly derived from gene-poor, repeat-rich regions in genomes (Weiberg et al., 2013) and plant targets of sRNAs are typically associated with immune responses (Dong et al., 2015).

To date, sRNA effectors from necrotrophic fungi have largely been reported from B. cinerea. The sRNAs Bc-siR3.1, Bc-siR3.2, and Bc-siR5 are the most abundant sRNAs during infection of tomato and Arabidopsis (Weiberg et al., 2013). These sRNAs specifically target a peroxiredoxin (oxidative stress-related gene), mitogen activated protein kinases (MPK1, MPK2, MPKKK4), and a cell wall-associated kinase (WAK) (Weiberg et al., 2013). These plant targets of fungal sRNAs are known components of immune responses; oxidative burst and signal transduction pathways. Thus, their silencing results in enhanced susceptibility to the fungus (Weiberg et al., 2013). Another sRNA, BcsiR37, can lead to silencing of Arabidopsis WRKY transcription factors, receptor-like kinases, and cell wall modifying enzymes, all leading to suppression of plant immunity against the fungus (Wang et al., 2017).

In S. sclerotiorum, sRNA sequencing of the fungus in vitro and during infection of Arabidopsis and common bean (Phaseolus vulgaris) revealed a group of fungal sRNAs that were secreted specifically in planta (Derbyshire et al., 2019). These sRNAs are predicted to target and suppress plant genes that are associated with quantitative disease resistance during infection (Derbyshire et al., 2019). In particular, mutations of two sRNA targets, encoding kinase genes SERK2 and SNAK2, increased susceptibility to $S$. sclerotiorum, suggesting that these sRNA targets contribute to disease resistance (Derbyshire et al., 2019). The role of sRNA in plant-pathogen interactions is an emerging field of plant pathology, and continued advances in sequencing technologies followed by functional characterization will likely reveal a broad utilization of these effector-like molecules across fungal taxa.

\section{CONCLUSION AND FUTURE PERSPECTIVES}

Necrotrophic fungal pathogens of plants were previously considered to cause cell death with simplistic mechanisms by secreting phytotoxic molecules and degrading plant cell walls. Recent bioinformatic advances and functional studies have accelerated the discovery of virulence factors in necrotrophs, including proteinaceous effectors, HSTs, and sRNA effectors, revealing that necrotrophs utilize a broad range of sophisticated virulence mechanisms during infection of plants (Figure 1). Our understanding of necrotrophic effectors is improving and

\section{REFERENCES}

Abeysekara, N. S., Friesen, T. L., Keller, B., and Faris, J. D. (2009). Identification and characterization of a novel host-toxin interaction in the wheat-Stagonospora nodorum pathosystem. Theor. Appl. Genet. 120, 117-126. doi: 10.1007/s00122009-1163-6 studies have revealed that these molecules are capable of both subverting and hijacking plant physiological processes to their advantage, including PCD. While PCD mechanisms are successfully deployed by plants that recognize biotrophic and hemibiotrophic effectors, necrotrophic effectors evolved to manipulate plant $\mathrm{PCD}$ and other immune responses to promote susceptibility. As necrotrophic fungi continue to cause significant crop losses worldwide, it is essential to improve our understanding of these molecules and their plant targets to identify novel modes of resistance against these pathogens.

To date, qualitative and robust genetic resistance to necrotrophic fungi is lacking in plants, aside from a few plant genotypes that are insensitive to fungal HSTs. Similarly, quantitative resistance against necrotrophs has shown limited efficiency and complicate breeding efforts. However, the recent discovery of sRNA cross-talk between plants and fungi has opened new avenues for disease control. Multiple fungal pathogens have now been shown to uptake environmental RNAs, leading to the silencing of specific fungal genes. Thus, plants can be weaponized to target virulence factors of necrotrophic fungi, including necrotrophic effectors. Spray-induced gene silencing is also showing promise as an RNAi tool.

Lastly, while many necrotrophic effectors manipulate plant PCD, the biochemical context of PCD in plants is poorly understood (Kabbage et al., 2017). We propose that necrotrophic effectors can be used as a valuable tool to uncover plant PCD components. A mechanistic understanding of how effectors trigger PCD, and how PCD can be prevented, is likely to have implications beyond plant-fungal interactions. In conclusion, there is a wealth of potential applications of plant-fungal necrotrophic effector research in disease control, basic plant physiology, and fungal biology, so expanding our understanding of these molecules will greatly expedite these applications.

\section{AUTHOR CONTRIBUTIONS}

DS and MR reviewed and evaluated the relevant literature, generated the figures, and created the tables. DS wrote the manuscript with significant contributions from MR, MK, and DLS. All authors contributed to the article and approved the submitted version.

\section{FUNDING}

This work was supported by the Wisconsin Soybean Marketing Board and the USDA National Institute of Food and Agriculture - National Sclerotinia Initiative (Award \# 58-3060-8-023) to MK and DLS.

Arunachalam, C., and Doohan, F. M. (2013). Trichothecene toxicity in eukaryotes: cellular and molecular mechanisms in plants and animals. Toxicol. Lett. 217, 149-158. doi: 10.1016/j.toxlet.2012.12.003

Bae, H., Kim, M. S., Sicher, R. C., Bae, H. J., and Bailey, B. A. (2006). Necrosis- and ethylene-inducing peptide from Fusarium oxysporum induces a complex cascade of transcripts associated with signal transduction and cell 
death in Arabidopsis. Plant Physiol. 141, 1056-1067. doi: 10.1104/pp.106. 076869

Bailey, B. (1995). Purification of a protein from culture filtrates of Fusarium oxysporum that induces ethylene and necrosis in leaves of Erythroxylum coca. Phytopathology 85, 1250-1255. doi: 10.1094/Phyto-85-1250

Bárány, I., Berenguer, E., Solís, M. T., Pérez-Pérez, Y., Santamaría, M. E., Crespo, J. L., et al. (2018). Autophagy is activated and involved in cell death with participation of cathepsins during stress-induced microspore embryogenesis in barley. J. Exp. Bot. 69, 1387-1402. doi: 10.1093/jxb/erx455

Ben M'Barek, S., Cordewener, J. H., van der Lee, T. A., America, A. H., Mirzadi Gohari, A., et al. (2015). Proteome catalog of Zymoseptoria tritici captured during pathogenesis in wheat. Fungal Genet. Biol. 79, 42-53. doi: 10.1016/j.fgb. 2015.04.018

Bhadauria, V., Banniza, S., Vandenberg, A., Selvaraj, G., and Wei, Y. (2013). Overexpression of a novel biotrophy-specific Colletotrichum truncatum effector, CtNUDIX, in hemibiotrophic fungal phytopathogens causes incompatibility with their host plants. Eukaryot. Cell 12, 2-11. doi: 10.1128/EC.00192-12

Bhadauria, V., MacLachlan, R., Pozniak, C., and Banniza, S. (2015). Candidate effectors contribute to race differentiation and virulence of the lentil anthracnose pathogen Colletotrichum lentis. BMC Genomics 16:628. doi: 10 . 1186/s12864-015-1836-2

Bi, K., Scalschi, L., Namrata Jaiswal, G., Frid, R., Zhu, W., Masrati, G., et al. (2020). The Botrytis cinerea Crh transglycosylae is a cytoplasmic effector triggering plant cell death and defense response. bioRxiv [Preprint]. doi: 10.1101/2020.06. 23.166843

Binet, M. N., Humbert, C., Lecourieux, D., Vantard, M., and Pugin, A. (2001). Disruption of microtubular cytoskeleton induced by cryptogein, an elicitor of hypersensitive response in tobacco cells. Plant Physiol. 125, 564-572. doi: $10.1104 /$ pp.125.2.564

Brandwagt, B. F., Mesbah, L. A., Takken, F. L., Laurent, P. L., Kneppers, T. J., Hille, J., et al. (2000). A longevity assurance gene homolog of tomato mediates resistance to Alternaria alternata f. sp. lycopersici toxins and fumonisin B1. Proc. Natl. Acad. Sci. U.S.A. 97, 4961-4966. doi: 10.1073/pnas.97.9.4961

Brent, K. J., and Hollomon, D. W. (2007). Fungicide Resistance in Crop Pathogens: How Can it be Managed? 2nd, revised Edn. Brussels: Fungicide Resistance Action Committee.

Brosch, G., Ransom, R., Lechner, T., Walton, J. D., and Loidl, P. (1995). Inhibition of maize histone deacetylases by $\mathrm{HC}$ toxin, the host-selective toxin of Cochliobolus carbonum. Plant Cell 7, 1941-1950. doi: 10.1105/tpc.7.11.1941

Buist, G., Steen, A., Kok, J., and Kuipers, O. P. (2008). LysM, a widely distributed protein motif for binding to (peptido)glycans. Mol. Microbiol. 68, 838-847. doi: 10.1111/j.1365-2958.2008.06211.x

Chang, H.-X., Domier, L. L., Radwan, O., Yendrek, C. R., Hudson, M. E., and Hartman, G. L. (2016). Identification of multiple phytotoxins produced by Fusarium virguliforme including a phytotoxic effector (FvNIS1) associated with sudden death syndrome foliar symptoms. Mol. Plant Microbe. Interact. 29, 96-108. doi: 10.1094/MPMI-09-15-0219-R

Charova, S. N., Dölfors, F., Holmquist, L., Moschou, P. N., Dixelius, C., and Tzelepis, G. (2020). The RsRlpA effector Is a protease inhibitor promoting Rhizoctonia solani virulence through suppression of the hypersensitive response. Int. J. Mol. Sci. 21:8070. doi: 10.3390/ijms21218070

Chen, H., Quintana, J., Kovalchuk, A., Ubhayasekera, W., and Asiegbu, F. O. (2015). A cerato-platanin-like protein HaCPL2 from Heterobasidion annosum sensu stricto induces cell death in Nicotiana tabacum and Pinus sylvestris. Fungal Genet. Biol. 84, 41-51. doi: 10.1016/j.fgb.2015.09.007

Ciuffetti, L. M., Manning, V. A., Pandelova, I., Betts, M. F., and Martinez, J. P. (2010). Host-selective toxins, PtrToxA and PtrToxB, as necrotrophic effectors in the Pyrenophora tritici-repentis-wheat interaction. New Phytol. 187, 911-919. doi: $10.1111 / \mathrm{j} .1469-8137.2010 .03362 . \mathrm{x}$

Corrêa, A., Staples, R. C., and Hoch, H. C. (1996). Inhibition of thigmostimulated cell differentiation with RGD-peptides in Uromyces germlings. Protoplasma 194, 91-102. doi: 10.1007/BF01273171

Corsi, B., Percival-Alwyn, L., Downie, R. C., Venturini, L., Iagallo, E. M., Mantello, C. C., et al. (2020). Genetic analysis of wheat sensitivity to the ToxB fungal effector from Pyrenophora tritici-repentis, the causal agent of tan spot. Theor. Appl. Genet. 133, 935-950.

Cowger, C., Ward, B., Brown-Guedira, G., and Brown, J. (2020). Role of effectorsensitivity gene interactions and durability of quantitative resistance to Septoria nodorum blotch in eastern U.S. wheat. Front. Plant Sci. 11:155. doi: 10.3389/ fpls.2020.00155

Dallal-Bashi, Z., Hegedus, D. D., Buchwaldt, L., Rimmer, S. R., and Borhan, M. H. (2010). Expression and regulation of Sclerotinia sclerotiorum necrosis and ethylene-inducing peptides (NEPs). Mol. Plant Pathol. 11, 43-53. doi: 10.1111/ j.1364-3703.2009.00571.x

de Jonge, R., van Esse, H. P., Kombrink, A., Shinya, T., Desaki, Y., Bours, R., et al. (2010). Conserved fungal LysM effector Ecp6 prevents chitin-triggered immunity in plants. Science 329, 953-955. doi: 10.1126/science.1190859

de Lamotte, F., Duviau, M. P., Sanier, C., Thai, R., Poncet, J., Bieysse, D., et al. (2007). Purification and characterization of cassiicolin, the toxin produced by Corynespora cassiicola, causal agent of the leaf fall disease of rubber tree. J. Chromatogr. B Analyt. Technol. Biomed. Life Sci. 849, 357-362. doi: 10.1016/ j.jchromb.2006.10.051

Denton-Giles, M., McCarthy, H., Sehrish, T., Dijkwel, Y., Mesarich, C. H., Bradshaw, R. E., et al. (2020). Conservation and expansion of a necrosisinducing small secreted protein family from host-variable phytopathogens of the Sclerotiniaceae. Mol. Plant Pathol. 21, 512-526. doi: 10.1111/mpp. 12913

Déon, M., Fumanal, B., Gimenez, S., Bieysse, D., Oliveira, R. R., Shuib, S. S., et al. (2014). Diversity of the cassiicolin gene in Corynespora cassiicola and relation with the pathogenicity in Hevea brasiliensis. Fungal Biol. 18, 32-47. doi: 10.1016/j.funbio.2013.10.011

Derbyshire, M., Denton-Giles, M., Hegedus, D., Seifbarghy, S., Rollins, J., van Kan, J., et al. (2017). The complete genome sequence of the phytopathogenic fungus Sclerotinia sclerotiorum reveals insights into the genome architecture of broad host range pathogens. Genome Biol. Evol. 9, 593-618. doi: 10.1093/gbe/evx030

Derbyshire, M., Mbengue, M., Barascud, M., Navaud, O., and Raffaele, S. (2019). Small RNAs from the plant pathogenic fungus Sclerotinia sclerotiorum highlight host candidate genes associated with quantitative disease resistance. Mol. Plant Pathol. 20, 1279-1297. doi: 10.1111/mpp.12841

Desmond, O. J., Manners, J. M., Stephens, A. E., MacLean, D. J., Schenk, P. M., Gardiner, D. M., et al. (2008). The Fusarium mycotoxin deoxynivalenol elicits hydrogen peroxide production, programmed cell death and defense responses in wheat. Mol. Plant Pathol. 9, 435-445. doi: 10.111/j.1364-3703.2008. 00475.X

Diamond, M., Reape, T. J., Rocha, O., Doyle, S. M., Kacprzyk, J., Doohan, F. M., et al. (2013). The Fusarium mycotoxin deoxynivalenol can inhibit plant apoptosis-like programmed cell death. PLoS One 8:e69542. doi: 10.1371/ journal.pone.0069542

Dölfors, F., Holmquist, L., Dixelius, C., and Tzelepis, G. (2019). A LysM effector protein from the basidiomycete Rhizoctonia solani contributes to virulence through suppression of chitin-triggered immunity. Mol. Genet. Genomics 294, 1211-1218. doi: 10.1007/s00438-019-01573-9

Dong, S., Raffaele, S., and Kamoun, S. (2015). The two-speed genomes of filamentous pathogens: Waltz with plants. Curr. Opin. Genet. Dev. 35, 57-65. doi: 10.1016/j.gde.2015.09.001

Dunkle, L. D., and Macko, V. (1995). Peritoxins and their effects on Sorghum. Can. J. Bot. 73, S444-S452. doi: 10.1139/b95-281

El Oirdi, M., El Rahman, T. A., Rigano, L., El Hadrami, A., Rodriguez, M. C., Daayf, F., et al. (2011). Botrytis cinerea manipulates the antagonistic effects between immune pathways to promote disease development in tomato. Plant Cell 23, 2405-2421. doi: 10.1105/tpc.111.083394

Evans, J. H., Gerber, S. H., Murray, D., and Leslie, C. C. (2004). The calcium binding loops of the cytosolic phospholipase A2 C2 domain specify targeting to Golgi and ER in live cells. Mol. Biol. Cell 15, 371-383. doi: 10.1091/mbc.e03-05-0338

Faris, J. D., Friesen, T. L., Lu, H., Reddy, L., Zhang, Z., Liu, Z., et al. (2007). "Genetic analysis of host-toxin interactions in the wheat-Stagonospora nodorum pathosystem," in Proceedings of the Meeting Abstract National Wheat Genomics Conference Abstracts, Tulln, 11.

Faris, J. D., Zhang, Z., Lu, S., Reddy, L., Cloutier, S., Fellers, J. P., et al. (2010). A unique wheat disease resistance-like gene governs effector-triggered susceptibility to necrotrophic pathogens. Proc. Natl. Acad. Sci. U.S.A. 107, 13544-13549. doi: 10.1073/pnas.1004090107

Fasoyin, O. E., Yang, K., Qiu, M., Wang, B., Wang, S., and Wang, S. (2019). Regulation of morphology, aflatoxin production, and virulence of Aspergillus flavus by the major nitrogen regulatory gene areA. Toxins 11:718. doi: 10.3390/ toxins 11120718 
Figueroa, M., Manning, V. A., Pandelova, I., and Ciuffetti, L. M. (2015). Persistence of the host-selective toxin Ptr ToxB in the apoplast. Mol. Plant Microbe. Interact. 28, 1082-1090. doi: 10.1094/MPMI-05-15-0097-R

Flor, H. H. (1971). Current status of the gene-for-gene concept. Annu. Rev. Phytopathol. 9, 275-296.

Fones, H. N., Bebber, D. P., Chaloner, T. M., Kay, W. T., Steinberg, G., and Gurr, S. J. (2020). Threats to global food security from emerging fungal and oomycete crop pathogens. Nat. Food 1, 332-342. doi: 10.1038/s43016-020-0075-0

Fountain, J. C., Scully, B. T., Ni, X., Kemerait, R. C., Lee, R. D., Chen, Z.-Y., et al. (2014). Environmental influences on maize-Aspergillus flavus interactions and aflatoxin production. Front. Microbiol. 5:40. doi: 10.3389/fmicb.2014.00040

Frías, M., González, C., and Brito, N. (2011). BcSpl1, a cerato-platanin family protein, contributes to Botrytis cinerea virulence and elicits the hypersensitive response in the host. New Phytol. 192, 483-495. doi: 10.1111/j.1469-8137.2011. 03802.x

Frías, M., González, M., González, C., and Brito, N. (2016). BcIEB1, a Botrytis cinerea secreted protein, elicits a defense response in plants. Plant Sci. 250, 115-124. doi: 10.1016/j.plantsci.2016.06.009

Frías, M., González, M., González, C., and Brito, N. (2019). A 25-residue peptide from Botrytis cinerea xylanase BcXyn11a elicits plant defenses. Front. Plant Sci. 10:474. doi: 10.3389/fpls.2019.00474

Friesen, T. L., Chu, C., Xu, S. S., and Faris, J. D. (2012). SnTox5-Snn5: a novel Stagonospora nodorum effector-wheat gene interaction and its relationship with the SnToxA-Tsn1 and SnTox3-Snn3-B1 interactions. Mol. Plant Pathol. 13, 1101-1109. doi: 10.1111/j.1364-3703.2012.00819.x

Friesen, T. L., and Faris, J. D. (2004). Molecular mapping of resistance to Pyrenosphora tritici-repentis race 5 and sensitivity to PtrToxB in wheat. Theor. Appl. Genet. 109, 464-471. doi: 10.1007/s00122-004-1678-9

Friesen, T. L., Meinhardt, S. W., and Faris, J. D. (2007). The Stagonospora nodorumwheat pathosystem involves multiple proteinaceous host-selective toxins and corresponding host sensitivity genes that interact in an inverse gene-for-gene manner. Plant J. 51, 681-692. doi: 10.1111/j.1365-313X.2007.03166.x

Friesen, T. L., Stukenbrock, E. H., Liu, Z., Meinhardt, S., Ling, H., Faris, J. D., et al. (2006). Emergence of a new disease as a result of interspecific virulence gene transfer. Nature 38, 953-956. doi: 10.1038/ng1839

Gao, F., Zhang, B.-S., Zhao, J.-H., Huang, J.-F., Jia, P.-S., Wang, S., et al. (2019). Deacetylation of chitin oligomers increases virulence in soil-borne fungal pathogens. Nat. Plants 5, 1167-1176.

Gao, Y., Faris, J. D., Liu, Z., Kim, Y. M., Syme, R. A., Oliver, R. P., et al. (2015). Identification and characterization of the SnTox6-Snn6 interaction in the Parastagonospora nodorum-wheat pathosystem. Mol. Plant Microbe Interact. 28, 615-625. doi: 10.1094/MPMI-12-14-0396-R

Gfeller, A., Dubugnon, L., Liechti, R., and Farmer, E. E. (2010). Jasmonate biochemical pathway. Sci. Signal. 3:cm3. doi: 10.1126/scisignal.3109cm3

Giraldo, M. C., and Valent, B. (2013). Filamentous plant pathogen effectors in action. Nat. Rev. Microbiol. 11, 800-814. doi: 10.1038/nrmicro3119

Glazebrook, J. (2005). Contrasting mechanisms of defense against biotrophic and necrotrophic pathogens. Annu. Rev. Phytopathol. 43, 205-227. doi: 10.1146/ annurev.phyto.43.040204.135923

González, M., Brito, N., and González, C. (2017). The Botrytis cinerea elicitor protein $\mathrm{BcIEB} 1$ interacts with the tobacco PR5-family protein osmotin and protects the fungus against its antifungal activity. New Phytol. 215, 397-410. doi: $10.1111 / \mathrm{nph} .14588$

Jones, J. D. J., and Dangl, J. L. (2006). The plant immune system. Nature 444, 323-329. doi: 10.1038/nature05286

Kabbage, M., Kessens, R., Bartholomay, L. C., and Williams, B. (2017). The life and death of a plant cell. Annu. Rev. Plant Biol. 68, 375-404. doi: 10.1146/annurevarplant-043015-111655

Kabbage, M., Williams, B., and Dickman, M. B. (2013). Cell death control: the interplay of apoptosis and autophagy in the pathogenicity of Sclerotinia sclerotiorum. PLoS Pathog. 9:e1003287. doi: 10.1371/journal.ppat.1003287

Kabbage, M., Yarden, O., and Dickman, M. B. (2015). Pathogenic attributes of Sclerotinia sclerotiorum: switching from a biotrophic to necrotrophic lifestyle. Plant Sci. 233, 53-60. doi: 10.1016/j.plantsci.2014.12.018

Kaku, H., Nishizawa, Y., Ishii-Minami, N., Akimoto-Tomiyama, C., Dohmae, N., Takio, K., et al. (2006). Plant cells recognize chitin fragments for defense signaling through a plasma membrane receptor. Proc. Natl. Acad. Sci. U.S.A. 103, 11086-11091. doi: 10.1073/pnas.0508882103
Kars, I., Krooshof, G. H., Wagemakers, L., Joosten, R., Benen, J. A., and van Kan, J. A. (2005). Necrotizing activity of five Botrytis cinerea endopolygalacturonases produced in Pichia pastoris. Plant J. 43, 213-225. doi: 10.1111/j.1365-313X. 2005.02436.x

Keller, N. P. (2019). Fungal secondary metabolism: regulation, function and drug discovery. Nat. Rev. Microbiol. 17, 167-180.

Kelley, R. Y., Williams, W. P., Mylroie, J. E., Boykin, D. L., Harper, J. W., Windham, G. L., et al. (2012). Identification of maize genes associated with host plant resistance or susceptibility to Aspergillus flavus infection and aflatoxin accumulation. PLoS One 7:e36892. doi: 10.1371/journal.pone.0036892

Kessler, S. C., Zhang, X., McDonald, M. C., Gilchrist, C., Lin, Z., Rightmyer, A., et al. (2020). Victorin, the host-selective cyclic peptide toxin from the oat pathogen Cochliobolus victoriae, is ribosomally encoded. Proc. Natl. Acad. Sci. U.S.A. 117, 24243-24250. doi: 10.1073/pnas.2010573117

Kleemann, J., Rincon-Rivera, L. J., Takahara, H., Neumann, U., Ver Loren van Themaat, E., van der Does, H. C., et al. (2012). Sequential delivery of hostinduced virulence effectors by appressoria and intracellular hyphae of the phytopathogen Colletotrichum higginsianum. PLoS Pathog. 8:e1002643. doi: 10. 1371/journal.ppat.1002643

Koeck, M., Hardham, A. R., and Dodds, P. N. (2011). The role of effectors of biotrophic and hemibiotrophic fungi in infection. Cell. Microbiol. 13, 18491857. doi: 10.1111/j.1462-5822.2011.01665.x

Kombrink, A., Rovenich, H., Shi-Kunne, X., Rojas-Padilla, E., van den Berg, G. C., Domazakis, E., et al. (2017). Verticillium dahliae LysM effectors differentially contribute to virulence on plant hosts. Mol. Plant Pathol. 18, 596-608. doi: 10.1111/mpp. 12520

Kunkel, B. N., and Brooks, D. M. (2002). Cross talk between signaling pathways in pathogen defense. Curr. Opin. Plant Biol. 5, 325-331. doi: 10.1016/s13695266(02)00275-3

Lacomme, C., and Santa Cruz, S. (1999). Bax-induced cell death in tobacco is similar to the hypersensitive response. Proc. Natl. Acad. Sci. U.S.A. 96, 79567961. doi: 10.1073/pnas.96.14.7956

Lam, E., Kato, N., and Lawton, M. (2001). Programmed cell death, mitochondria and the plant hypersensitive response. Nature 411, 848-853. doi: 10.1038/ 35081184

Laxalt, A. M., ter Riet, B., Verdonk, J. C., Parigi, L., Tameling, W. I., Vossen, J., et al. (2001). Characterization of five tomato phospholipase D cDNAs: rapid and specific expression of LePLD betal on elicitation with xylanase. Plant J. 26, 237-247. doi: 10.1046/j.1365-313x.2001.01023.x

Le Marquer, M., San Clemente, H., Roux, C., Savelli, B., and Frei Dit Frey, N. (2019). Identification of new signalling peptides through a genome-wide survey of 250 fungal secretomes. BMC Genomics 20:64. doi: 10.1186/s12864-018-5414-2

Levin, E., Raphael, G., Ma, J., Ballester, A. R., Feygenberg, O., Norelli, J., et al. (2019). Identification and functional analysis of NLP-encoding genes from the postharvest pathogen Penicillium expansum. Microorganisms 7:175. doi: 10.3390/microorganisms7060175

Li, H., Fu, Y., Jiang, D., Li, G., Ghabrial, S. A., and Yi, X. (2008). Down-regulation of Sclerotinia sclerotiorum gene expression in response to infection with Sclerotinia sclerotiorum debilitation-associated RNA virus. Virus Res. 135, 95-106. doi: 10.1016/j.virusres.2008.02.011

Li, S., Peng, X., Wang, Y., Hua, K., Xing, F., Zheng, Y., et al. (2019). The effector AGLIP1 in Rhizoctonia solani AG1 IA triggers cell death in plants and promotes disease development through inhibiting PAMP-triggered immunity in Arabidopsis thaliana. Front. Microbiol. 10:2228. doi: 10.3389/fmicb.2019. 02228

Li, Z., Yin, Z., Fan, Y., Xu, M., Kang, Z., and Huang, L. (2015). Candidate effector proteins of the necrotrophic apple canker pathogen Valsa mali can suppress BAX-induced PCD. Front. Plant Sci. 6:579. doi: 10.3389/fpls.2015.00579

Litzenberger, S. C. (1949). Nature of susceptibility to Helminthosporium victoriae and resistance to Puccinia coronata in Victoria oats. Phytopathology 3, 300-318.

Liu, Z., Faris, J. D., Oliver, R. P., Tan, K. C., Solomon, P. S., McDonald, M. C., et al. (2009). SnTox3 acts in effector triggered susceptibility to induce disease on wheat carrying the Snn3 gene. PLoS Pathog. 5:e1000581. doi: 10.1371/journal. ppat.1000581

Liu, Z., Gao, Y., Kim, Y. M., Faris, J. D., Shelver, W. L., de Wit, P. J., et al. (2016). SnTox1, a Parastagonospora nodorum necrotrophic effector, is a dual-function protein that facilitates infection while protecting from wheatproduced chitinases. New Phytol. 211, 1052-1064. doi: 10.1111/nph.13959 
Liu, Z., Zhang, Z., Faris, J. D., Oliver, R. P., Syme, R., McDonald, M. C., et al. (2012). The cysteine rich necrotrophic effector SnToxl produced by Stagonospora nodorum triggers susceptibility of wheat lines harboring Snn1. PLoS Pathog. 8:e1002467. doi: 10.1371/journal.ppat.1002467

Liu, Z. H., Faris, J. D., Meinhardt, S. W., Ali, S., Rasmussen, J. B., and Friesen, T. L. (2004). Genetic and physical mapping of a gene conditioning sensitivity in wheat to a partially purified host-selective toxin produced by Stagonospora nodorum. Phytopathology 94, 1056-1060. doi: 10.1094/PHYTO.2004.94.10. 1056

Lopez, D., Ribeiro, S., Label, P., Fumanal, B., Venisse, J. S., Kohler, A., et al. (2018). Genome-wide analysis of Corynespora cassiicola leaf fall disease putative effectors. Front. Microbiol. 9:276. doi: 10.3389/fmicb.2018. 00276

Lorang, J., Kidarsa, T., Bradford, C. S., Gilbert, B., Curtis, M., Tzeng, S.-C., et al. (2012). Tricking the guard: exploiting plant defense for disease susceptibility. Science 338, 659-662. doi: 10.1126/science. 1226743

Lorang, J. M., Sweat, T. A., and Wolpert, T. J. (2007). Plant disease susceptibility conferred by a "resistance" gene. Proc. Natl. Acad. Sci. U.S.A. 104, 14861-14866. doi: 10.1073/pnas.0702572104

Lu, S., Gillian Turgeon, B., and Edwards, M. C. (2015). A ToxA-like protein from Cochliobolus heterostrophus induces light-dependent leaf necrosis and acts as a virulence factor with host selectivity on maize. Fungal Genet. Biol. 81, 12-24. doi: 10.1016/j.fgb.2015.05.013

Luciano-Rosario, D., Keller, N. P., and Jurick, W. M. II (2020). Penicillium expansum: biology, omics, and management tools for a global postharvest pathogen causing blue mould of pome fruit. Mol. Plant Pathol. 21, 1391-1404. doi: $10.1111 / \mathrm{mpp} .12990$

Manning, V. A., and Ciuffetti, L. M. (2005). Localization of PtrToxA produced by Prenophora tritici-repentis reveals protein import into wheat mesophyll cells. Plant Cell 17, 3203-3212. doi: 10.1105/tpc.105.035063

Manning, V. A., and Ciuffetti, L. M. (2015). Necrotrophic effector epistasis in the Pyrenophora tritici-repentis-wheat interaction. PLoS One 10:e0123548. doi: 10.1371/journal.pone.0123548

Manning, V. A., Hardison, L. K., and Ciuffetti, L. M. (2007). PtrToxA interacts with a chloroplast-localized protein. Mol. Plant Microbe Interact. 20, $168-177$.

Marshall, R., Kombrink, A., Motteram, J., Loza-Reyes, E., Lucas, J., HammondKosack, K. E., et al. (2011). Analysis of two in planta expressed LysM effector homologs from the fungus Mycosphaerella graminicola reveals novel functional properties and varying contributions to virulence on wheat. Plant Physiol. 156, 756-769. doi: 10.1104/pp.111.176347

Martínez-Cruz, J., Romero, D., Hierrezuelo, J., Thon, M., de Vicente, A., and Pérez-García, A. (2021). Effectors with chitinase activity (EWCAs), a family of conserved, secreted fungal chitinases that suppress chitin-triggered immunity. Plant Cell. doi: 10.1093/plcell/koab011 [Epub ahead of print]

McDonald, M. C., Ahren, D., Simpfendorfer, S., Milgate, A., and Solomon, P. S. (2018). The discovery of the virulence gene ToxA in the wheat and barley pathogen Bipolaris sorokiniana. Mol. Plant Pathol. 19, 432-439. doi: 10.1111/ mpp. 12535

McLennan, A. G. (2006). The nudix hydrolase superfamily. Cell. Mol. Life Sci. 63, 123-143. doi: 10.1007/s00018-005-5386-7

Meehan, F., and Murphy, H. C. (1946). A new Helminthosporium blight of oats. Science 104, 413-414. doi: 10.1126/science.104.2705.413

Meena, M., and Samal, S. (2019). Alternaria host-specific (HSTs) toxins: an overview of chemical characterization, target sites, regulation and their toxic effects. Toxicol. Rep. 6, 745-758. doi: 10.1016/j.toxrep.2019. 06.021

Misas-Villamil, J. C., van der Hoorn, R. A., and Doehlemann, G. (2016). Papainlike cysteine proteases as hubs in plant immunity. New Phytol. 212, 902-907. doi: 10.1111/nph.14117

Miya, A., Albert, P., Shinya, T., Desaki, Y., Ichimura, K., Shirasu, K., et al. (2007). CERK1, a LysM receptor kinase, is essential for chitin elicitor signaling in Arabidopsis. Proc. Natl. Acad. Sci. U.S.A. 104, 19613-19618. doi: 10.1073/pnas. 0705147104

Mudge, A. M., Dill-Macky, R., Dong, Y., Gardiner, D. M., White, R. G., and Manners, J. M. (2006). A role for the mycotoxin deoxynivalenol in stem colonisation during crown rot disease of wheat caused by Fusarium graminearum and F. pseudograminearum. Physiol. Mol. Plant Pathol. 69, 73-85. doi: 10.1016/j.pmpp.2007.01.003

Nagy, E. D., and Bennetzen, J. L. (2008). Pathogen corruption and site-directed recombination at a plant disease resistance gene cluster. Genome Res. 18, 1918-1923. doi: 10.1101/gr.078766.108

Noda, J., Brito, N., and González, C. (2010). The Botrytis cinerea xylanase Xyn11A contributes to virulence with its necrotizing activity, not with its catalytic activity. BMC Plant Biol. 10:38. doi: 10.1186/1471-2229-10-38

Nomura, H., Komori, T., Kobori, M., Nakahira, Y., and Shiina, T. (2008). Evidence for chloroplast control of external Ca2+-induced cytosolic Ca2+transients and stomatal closure. Plant J. 53, 988-998. doi: 10.1111/j.1365-313X.2007.03390.x

Nomura, H., Komori, T., Uemura, S., Kanda, Y., Shimotani, K., Nakai, K., et al. (2012). Chloroplast-mediated activation of plant immune signalling in Arabidopsis. Nat. Commun. 3:926. doi: 10.1038/ncomms1926

Oome, S., and Van den Ackerveken, G. (2014). Comparative and functional analysis of the widely occurring family of Nepl-like proteins. Mol. Plant Microbe Interact. 27, 1081-1094. doi: 10.1094/MPMI-04-14-0118-R

Ribeiro, S., Tran, D. M., Déon, M., Clément-Demange, A., Garcia, D., Soumahoro, M., et al. (2019). Gene deletion of Corynespora cassiicola cassiicolin Cas1 suppresses virulence in the rubber tree. Fungal Genet. Biol. 129, 101-114. doi: 10.1016/j.fgb.2019.05.004

Safrany, S. T., Ingram, S. W., Cartwright, J. L., Falck, J. R., McLennan, A. G., Barnes, L. D., et al. (1999). The diadenosine hexaphosphate hydrolases from Schizosaccharomyces pombe and Saccharomyces cerevisiae are homologues of the human diphosphoinositol polyphosphate phosphohydrolase. Overlapping substrate specificities in a MutT-type protein. J. Biol. Chem. 274, 21735-21740. doi: 10.1074/jbc.274.31.21735

Sanz-Martín, J. M., Pacheco-Arjona, J. R., Bello-Rico, V., Vargas, W. A., Monod, M., Díaz-Mínguez, J. M., et al. (2016). A highly conserved metalloprotease effector enhances virulence in the maize anthracnose fungus Colletotrichum graminicola. Mol. Plant Pathol. 17, 1048-1062. doi: 10.1111/mpp. 12347

Schwessinger, B., and Ronald, P. (2012). Plant innate immunity: perception of conserved microbial signatures. Annu. Rev. Plant Biol. 63, 451-482. doi: 10. 1146/annurev-arplant-042811-105518

Seifbarghi, S., Borhan, M. H., Wei, Y., Ma, L., Coutu, C., Bekkaoui, D., et al. (2020). Receptor-like kinases BAK1 and SOBIR1 are required for necrotizing activity of a novel group of Sclerotinia sclerotiorum necrosis-inducing effectors. Front. Plant Sci. 11:1021. doi: 10.3389/fpls.2020.01021

Shi, G., Friesen, T. L., Saini, J., Xu, S. S., Rasmussen, J. B., and Faris, J. D. (2015). The wheat Snn7 gene confers susceptibility on recognition of the Parastagonospora nodorum necrotrophic effector SnTox7. Plant Genome 8:eplantgenome2015.02.0007. doi: 10.3835/plantgenome2015.02.0007

Shimizu, T., Nakano, T., Takamizawa, D., Desaki, Y., Ishii-Minami, N., Nishizawa, Y., et al. (2010). Two LysM receptor molecules, CEBiP and OsCERK1, cooperatively regulate chitin elicitor signaling in rice. Plant J. 64, 204-214. doi: 10.1111/j.1365-313X.2010.04324.x

Silva, W. P. K., Wijesundera, R. L. C., Karunanayake, E. H., Jayasinghe, C. K., and Priyanka, U. M. S. (2000). New hosts of Corynespora cassiicola in Sri Lanka. Plant Dis. 84:202. doi: 10.1094/PDIS.2000.84.2.202D

Snini, S. P., Tannous, J., Heuillard, P., Bailly, S., Lippi, Y., Zehraoui, E., et al. (2016). Patulin is a cultivar-dependent aggressiveness factor favouring the colonization of apples by Penicillium expansum. Mol. Plant Pathol. 17, 920-930. doi: 10.1111/ mpp. 12338

Solomon, P. S., Lowe, R. G., Tan, K. C., Waters, O. D., and Oliver, R. P. (2006). Stagonospora nodorum: cause of Stagonospora nodorum blotch of wheat. Mol. Plant Pathol. 7, 147-156. doi: 10.1111/j.1364-3703.2006.00326.x

Sperschneider, J., Gardiner, D. M., Dodds, P. N., Tini, F., Covarelli, L., Singh, K. B., et al. (2016). EffectorP: predicting fungal effector proteins from secretomes using machine learning. New Phytol. 210, 743-761. doi: 10.1111/nph.13794

Staats, M., Van Baarlen, P., Schouten, A., and Van Kan, J. A. (2007). Functional analysis of NLP genes from Botrytis elliptica. Mol. Plant Pathol. 8, 209-214. doi: 10.1111/j.1364-3703.2007.00382.x

Stergiopoulos, I., Collemare, J., Mehrabi, R., and De Wit, P. J. (2013). Phytotoxic secondary metabolites and peptides produced by plant pathogenic Dothideomycete fungi. FEMS Microbiol. Rev. 37, 67-93. doi: 10.1111/j.15746976.2012.00349.x 
Tan, C. K., Oliver, P. R., Solomon, P. S., and Moffat, S. C. (2010). Proteinaceous necrotrophic effectors in fungal virulence. Funct. Plant Biol. 37, 907-912. doi: 10.1071/FP10067

Tang, L., Yang, G., Ma, M., Liu, X., Li, B., Xie, J., et al. (2020). An effector of a necrotrophic fungal pathogen targets the calcium-sensing receptor in chloroplasts to inhibit host resistance. Mol. Plant Pathol. 21, 686-701. doi: 10.1111/mpp.12922

Thomma, B. P., Nürnberger, T., and Joosten, M. H. (2011). Of PAMPs and effectors: the blurred PTI-ETI dichotomy. Plant Cell 23, 4-15. doi: 10.1105/tpc.110. 082602

Toruño, T. Y., Stergiopoulos, I., and Coaker, G. (2016). Plant-pathogen effectors: cellular probes interfering with plant defenses in spatial and temporal manners. Annu. Rev. Phytopathol. 54, 419-441. doi: 10.1146/annurev-phyto-080615100204

Touhami, N., Soukup, S. T., Schmidt-Heydt, M., Kulling, S. E., and Geisen, R. (2018). Citrinin as an accessory establishment factor of $P$. expansum for the colonization of apples. Int. J. Food Microbiol. 266, 224-233. doi: 10.1016/j. ijfoodmicro.2017.12.007

Tsuge, T., Harimoto, Y., Akimitsu, K., Ohtani, K., Kodama, M., Akagi, Y., et al. (2013). Host-selective toxins produced by the plant pathogenic fungus Alternaria alternata. FEMS Microbiol. Rev. 37, 44-66. doi: 10.1111/j.1574-6976. 2012.00350.x

Tuori, R. P., Wolpert, T. J., and Ciuffetti, L. M. (1995). Purification and immunological characterization of toxic components from cultures of Pyrenophora tritici-repentis. Mol. Plant Microbe Interact. 8, 41-48.

van den Burg, H. A., Harrison, S. J., Joosten, M. H., Vervoort, J., and de Wit, P. J. (2006). Cladosporium fulvum Avr4 protects fungal cell walls against hydrolysis by plant chitinases accumulating during infection. Mol. Plant Microbe Interact. 19, 1420-1430. doi: 10.1094/MPMI-19-1420

Vargas, W. A., Sanz Martín, J. M., Rech, G. E., Rivera, L. P., Benito, E. P., Díaz-Mínguez, J. M., et al. (2012). Plant defense mechanisms are activated during biotrophic and necrotrophic development of Colletotricum graminicola in maize. Plant Physiol. 158, 1342-1358. doi: 10.1104/pp.111.190397

Walton, J. D. (2006). HC-toxin. Phytochemistry 67, 1406-1413. doi: 10.1016/j. phytochem.2006.05.033

Wang, H., Li, J., Bostock, R. M., and Gilchrist, D. G. (1996). Apoptosis: a functional paradigm for programmed plant cell death induced by a hostselective phytotoxin and invoked during development. Plant Cell 8, 375-391. doi: $10.1105 /$ tpc.8.3.375

Wang, M., Weiberg, A., Dellota, E. Jr., Yamane, D., and Jin, H. (2017). Botrytis small RNA Bc-siR37 suppresses plant defense genes by cross-kingdom RNAi. RNA Biol. 14, 421-428. doi: 10.1080/15476286.2017.1291112

Wang, M., Weiberg, A., Lin, F. M., Thomma, B. P., Huang, H. D., and Jin, H. (2016). Bidirectional cross-kingdom RNAi and fungal uptake of external RNAs confer plant protection. Nat. Plants 2:16151. doi: 10.1038/nplants.2016.151

Wang, X., Li, Q., Niu, X., Chen, H., Xu, L., and Qi, C. (2009). Characterization of a canola $\mathrm{C} 2$ domain gene that interacts with $\mathrm{PG}$, an effector of the necrotrophic fungus Sclerotinia sclerotiorum. J. Exp. Bot. 60, 2613-2620. doi: 10.1093/jxb/ erp104

Weiberg, A., and Jin, H. (2015). Small RNAs - the secret agents of the plantpathogen interactions. Curr. Opin. Plant Biol. 26, 87-94. doi: 10.1016/j.pbi.2015. 05.033

Weiberg, A., Wang, M., Lin, F. M., Zhao, H., Zhang, Z., Kaloshian, I., et al. (2013). Fungal small RNAs suppress plant immunity by hijacking host RNA interference pathways. Science 342, 118-123. doi: 10.1126/science. 1239705

Wen, Z., Raffaello, T., Zeng, Z., Pavicic, M., and Asiegbu, F. O. (2019). Chlorophyll fluorescence imaging for monitoring effects of Heterobasidion parviporum small secreted protein induced cell death and in planta defense gene expression. Fungal Genet. Biol. 126, 37-49. doi: 10.1016/j.fgb.2019.02.003

Westrick, N. M., Smith, D. L., and Kabbage, M. (2021). Disarming the host: detoxification of plant defense compounds during fungal necrotrophy. Front. Plant Sci. doi: 10.3389/fpls.2021.651716 [Epub ahead of print].
Wibberg, D., Andersson, L., Tzelepis, G., Rupp, O., Blom, J., Jelonek, L., et al. (2016). Genome analysis of the sugar beet pathogen Rhizoctonia solani AG22IIIB revealed high numbers in secreted proteins and cell wall degrading enzymes. BMC Genomics 17:245. doi: 10.1186/s12864-016-2561-1

Williams, B., and Dickman, M. (2008). Plant programmed cell death: can't live with it; can't live without it. Mol. Plant Pathol. 9, 531-544. doi: 10.1111/j.1364-3703. 2008.00473.x

Williams, B., Kabbage, M., Kim, H. J., Britt, R., and Dickman, M. B. (2011). Tipping the balance: Sclerotinia sclerotiorum secreted oxalic acid suppresses host defenses by manipulating the host redox environment. PLoS Pathog. 7:e1002107. doi: 10.1371/journal.ppat.1002107

Wolpert, T. J., Dunkle, L. D., and Ciuffetti, L. M. (2002). Host-selective toxins and avirulence determinants: What's in a name? Annu. Rev. Phytopathol. 40, 251-285. doi: 10.1146/annurev.phyto.40.011402.114210

Wolpert, T. J., Macko, V., Acklin, W., Jaun, B., Seibl, J., Meili, J., et al. (1985). Structure of victorin C, the major host-selective toxin from Cochliobolus victoriae. Experientia 41, 1524-1529. doi: 10.1007/BF01964789

Xu, W., Shen, J., Dunn, C. A., Desai, S., and Bessman, M. J. (2001). The nudix hydrolases of Deinococcus radiodurans. Mol. Microbiol. 39, 286-290. doi: 10. 1046/j.1365-2958.2001.02267.x

Yang, G., Tang, L., Gong, Y., Xie, J., Fu, Y., Jiang, D., et al. (2018). A cerato-platanin protein SsCP1 targets plant PR1 and contributes to virulence of Sclerotinia sclerotiorum. New Phytol. 217, 739-755. doi: 10.1111/nph.14842

Yang, H., Yang, S., Li, Y., and Hua, J. (2007). The Arabidopsis BAP1 and BAP2 genes are general inhibitors of programmed cell death. Plant Physiol. 145, 135-146. doi: 10.1104/pp.107.100800

Yang, Y., Yang, X., Dong, Y., and Qiu, D. (2018). The Botrytis cinerea xylanase BcXyll modulates plant immunity. Front. Microbiol. 9:2535. doi: 10.3389/fmicb. 2018.02535

Yang, Y., Zhang, H., Li, G., Li, W., Wang, X., and Song, F. (2009). Ectopic expression of MgSM1, a Cerato-platanin family protein from Magnaporthe grisea, confers broad-spectrum disease resistance in Arabidopsis. Plant Biotechnol. J. 7, 763-777. doi: 10.1111/j.1467-7652.2009.00442.x

Yoshino, K., Irieda, H., Sugimoto, F., Yoshioka, H., Okuno, T., and Takano, Y. (2012). Cell death of Nicotiana benthamiana is induced by secreted protein NIS1 of Colletotrichum orbiculare and is suppressed by a homologue of CgDN3. Mol. Plant Microbe Interact. 25, 625-636.

Zhang, Y., Zhang, Y., Qiu, D., Zeng, H., Guo, L., and Yang, X. (2015). BcGs1, a glycoprotein from Botrytis cinerea, elicits defence response and improves disease resistance in host plants. Biochem. Biophys. Res. Commun. 457, 627-634. doi: 10.1016/j.bbrc.2015.01.038

Zhu, W., Ronen, M., Gur, Y., Minz-Dub, A., Masrati, G., Ben-Tal, N., et al. (2017). BcXYG1, a secreted xyloglucanase from Botrytis cinerea, triggers both cell death and plant immune responses. Plant Physiol. 175, 438-456. doi: 10.1104/pp.17. 00375

Zhu, W., Wei, W., Fu, Y., Cheng, J., Xie, J., Li, G., et al. (2013). A secretory protein of necrotrophic fungus Sclerotinia sclerotiorum that suppresses host resistance. PLoS One 8:e53901. doi: 10.1371/journal.pone.0053901

Zuppini, A., Navazio, L., Sella, L., Castiglioni, C., Favaron, F., and Mariani, P. (2005). An endopolygalacturonase from Sclerotinia sclerotiorum induces calcium-mediated signaling and programmed cell death in soybean cells. Mol. Plant Microbe Interact. 18, 849-855. doi: 10.1094/MPMI-18-0849

Conflict of Interest: The authors declare that the research was conducted in the absence of any commercial or financial relationships that could be construed as a potential conflict of interest.

Copyright (c) 2021 Shao, Smith, Kabbage and Roth. This is an open-access article distributed under the terms of the Creative Commons Attribution License (CC BY). The use, distribution or reproduction in other forums is permitted, provided the original author(s) and the copyright owner(s) are credited and that the original publication in this journal is cited, in accordance with accepted academic practice. No use, distribution or reproduction is permitted which does not comply with these terms. 